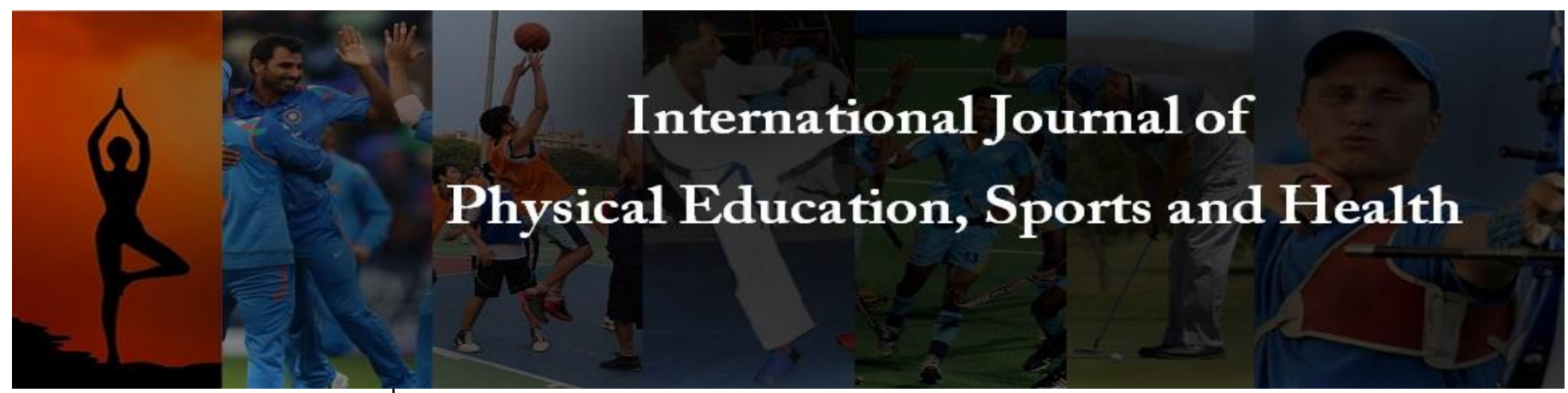

P-ISSN: 2394-1685

E-ISSN: 2394-1693

Impact Factor (ISRA): 5.38

IJPESH 2021; 8(2): 77-84

(C) 2021 IJPESH

www.kheljournal.com

Received: 07-01-2021

Accepted: 12-02-2021

Gustave Adolphe Messanga Department of PhilosophyPsychology-Sociology,

University of Dschang,

Cameroon

Aline Dounmejong Songong Department of PhilosophyPsychology-Sociology, University of Dschang,

Cameroon

Sylvestre Nzeuta Lontio Department of PhilosophyPsychology-Sociology, University of Dschang, Cameroon

\section{Effect of emotional intelligence on sensitivity to stereotype threat among girls learning to play football}

\author{
Gustave Adolphe Messanga, Aline Dounmejong Songong and Sylvestre \\ Nzeuta Lontio
}

DOI: https://doi.org/10.22271/kheljournal.2021.v8.i2b.2029

\section{Abstract}

This study assesses sensitivity to stereotype threat among girls learning to play football. It fits precisely in the perspective of works on the reduction factors of this phenomenon. It proposes emotional intelligence as a factor that can reduce sensitivity to this threat; hence the hypothesis: among girls learning to play football, high emotional intelligence reduces sensitivity to stereotype threat more than low emotional intelligence. Specifically, participants' exposure to an ingroup stereotype of incompetence was expected to impact them differently, depending on their level of emotional intelligence. This hypothesis was tested through an experiment carried out with 61 female pupils attending the Government Bilingual High School of Penka-Michel (Cameroon). That exeperiment was conducted in a natural setting, following the stereotype threat's experimental paradigm. The results do not support the hypothesis of the study, although it can be observed that the average performance of participants with high emotional intelligence is higher than that of their counterparts with low emotional intelligence (f (1, $61)=6.79 ; \mathrm{h}^{2}=.98 ; \mathrm{p}=.135>.05 ; \mathrm{t}=.63 ; \mathrm{p}=.532>.05 ; \mathrm{M}$ high $\mathrm{IE}=3566.67>\mathrm{M}$ low IE = 3433.72). It is concluded that emotional intelligence does not significantly reduce sensitivity to stereotype threat.

Keywords: stereotype threat, emotions, emotional intelligence, sensitivity to stereotype threat, performance

\section{Introduction}

Stereotypes are socially shared beliefs about the personal characteristics, personality traits and behaviors of the members of a group (Sales-Wuillemin, 2007) ${ }^{[42]}$. This cognitive dimension of intergroup representations is underpinned by the attribution of negative traits to individuals. Thus, when stereotypes are internalized and shared by the people who are their targets, they generate negative emotions that impact their working memory (Schmader et al., 2008) ${ }^{[44]}$. The consequence is the decline in their intellectual performance; hence the stereotype threat (Chateignier et al., 2011; De Meyer, 2015; Racky, 2013) ${ }^{[12,36,40]}$. If, since the pioneer work of Steele and Aronson (1995) ${ }^{[45]}$, the specialized literature has focused on establishing the existence of this threat and explaining its underlying mechanisms in various contexts and with different populations, one can observe that it is increasingly interested in strategies and factors that make it possible to reduce its negative impact on performance (Schmader et al., 2008) ${ }^{[44]}$. The present study is within that perspective.

\subsection{The stereotype threat}

The question underlying research on stereotype threat is formulated as follows: how do you explain that negative stereotypes can lead to reduced performance in stigmatized populations? (Chateignier, 2014) ${ }^{[13]}$ The two major explanations offered so far by the literature concern the way individuals process information relating to the task to be accomplished and the emotions generated by the threatening situation. Indeed, stereotype threat leads to a reduction in the capacity to process and filter relevant information for the accomplishment of the task (Schmader \& Johns, 2003) ${ }^{[43]}$. In principle, this filtration is ensured by the working memory which, because of the threat, sees its processing capacities reduced. The reason for this reduction is related to the fact that stereotype threat generates intrusive thoughts whose action 
consists of a congestion of the said memory. In fact, people ruminate on negative ideas about the threatening situation when the task makes the stereotype relevant. These ideas partly occupy their working memory and limit their processing capacities (Desmette et al., 2001) ${ }^{[18]}$. As a result, they would no longer have sufficient resources to effectively accomplish the task; hence the poor performance. This threat would involve negative emotions (Schmader et al., 2008) ${ }^{[44]}$. The deleterious effects of the negative stereotype have been experienced in the areas of cognitive performance among students from disadvantaged socioeconomic backgrounds, intellectual tasks among women and people belonging to ethnic minorities in mathematics, and mnemonic tasks among the elderly (Chateignier et al. al., 2009) ${ }^{[14]}$. The stereotype threat hypothesis states that a stereotype has the capacity to impact on the performance of individuals, due to its internalization (Dagot, 2007) ${ }^{[17]}$. The steadily declining performance of African-American students at Stanford University compared to their White peers in standardized tests is an illustration of this phenomenon. This decline in performance was due to the activation of the stereotype of incompetence of African Americans, when the test was presented as a tool to assess their intellectual abilities (Steele \& Aronson, 1995) ${ }^{[45]}$. The proof is that the average performance of their counterparts of the control group, to whom the test was presented as a simple laboratory exercise, was much better. In addition, no difference was observed between the performance of members of this control group and that of American participants of European origin, placed in the same non-stereotypical situation; hence the conclusion that the stereotype of black intellectual inferiority had an impact on their performance (Steele \& Aronson, 1995) ${ }^{[45]}$.

The literature reveals that many factors increase sensitivity to stereotype threat. These are: knowledge of the stereotype; awareness of this stereotype; its relevance relatively linked to a field of competence; identification with the stereotypical domain; and the difficulty of the task (Chateignier, 2014; Kinch, 2017) ${ }^{[13,28]}$. Research shows that identification with the stereotypical domain, relevance and stereotype threat are linked (Steele \& Aronson, 1995) ${ }^{[45]}$. The latter emerges when the average difficulty level of the test is directly above the abilities of the participants. On the other hand, if the task is easy, they will be less sensitive to the threat. These factors would be linked as part of a process. Their action inhibits the mobilization of the cognitive resources needed to perform a task and generates disturbances which are responsible for the decline in performance (O’Brien \& Crandall, 2003) ${ }^{[38]}$.

\subsection{Stereotype threat in football}

According to Grabow and Kühl (2019) ${ }^{[22]}$, football is the most popular men' sport in the world as opposed to women' sports. It was built around masculine physical attributes such as being muscular, robust, active, competitive, ambitious, strong, fast, aggressive, courageous or tough, and actions associated with a social construction of masculinity (Hill \& Azzarito, 2009) ${ }^{[25]}$. As a consequence, women' football is imbued with sexist stereotypes claiming that players are not made for this sport, and that men are better in this domain (Clément-Guillotin \& Fontayne, 2011) ${ }^{[16]}$, because their physical and psychological characteristics are not compatible with the practice of this manly sport, since they are portrayed as shy, gentle, tender or submissive people. In short, women' football is no exception to existing sexist divisions and conventional femininity. The consequence of these sexist stereotypes relating to the practice of sport in general is their negative impact on athletes' motor skills (Beilock \& McConnell, 2004) ${ }^{[4]}$. By way of illustration, Beilock et al. (2006) ${ }^{[6]}$ observe a drop in performance among men in sports designed as feminine (swimming or figure skating), while women, for their part, are under threat when the stereotype is associated with sports considered to be masculine (boxing, rugby, athletics or football). More specifically, the technical capacities of footballers decline when they are considered incompetent (Chalabaev et al., 2008) ${ }^{[10]}$.

The stereotype that women cannot play football affects their technical abilities when subjected to complex and demanding motor tasks such as precision in front of goals (Grabow \& Kühl, 2019) [22]. Specifically, those who remember the stereotype have lower motor skills than those who do not. The stereotype that the "real" football is always men' football (Pfiter, 2015: 565) ${ }^{[39]}$ challenges women' football. This sport is belittled, ridiculed and seen as inappropriate for women (Keller, 2018, cited by Grabow \& Kühl, 2019) ${ }^{[22]}$. These illustrative elements indicate that women who play football are confronted with the fact that this sport is stereotypically considered as masculine; hence the fact that they are sometimes seen as intruders. What factors are likely to reduce the psychological effects of this stereotyping?

\subsection{Strategies and factors for reducing the effects of stereotype threat: the implication of emotions}

Knowledge of the explanatory mechanisms of stereotype threat has given rise to reflection on factors that may reduce its effects. Reducing stereotype threat means deploying strategies to make individuals exposed less sensitive to a stereotype of inferiority in a domain. In this logic, research recommends the analysis of the evaluation context of stereotyped people and proposes the change of the description of the task as a first strategy (Good et al., 2003) ${ }^{[21]}$. This must be done in such a way that the stereotype is no longer invoked. Marx and Goff (2005) ${ }^{[34]}$ propose, for their part, to refer to individuals who have succeeded in the stereotyped domain. They also suggest having the test administered by a member of the stereotyped group; this strategy enabling to reduce the threat in the same way as teaching stereotype and its effects to stereotyped individuals, because it promotes knowledge of the stereotype (De Meyer, 2015) ${ }^{[36]}$. In this sense, literature proposes to focus on the target of the stereotype and to induce self-assertion, disidentification with the group or with the stereotyped domain and activation of individualization mechanisms (Ambady et al., 2004; Steele et al., 2002) ${ }^{[1]}$. Another strategy is to reallocate the anxiety felt to an external cause and reassess the threatening source (Johns et al., 2005) ${ }^{[27]}$.

In addition to the cognitive factors of sensitivity to stereotype threat, research is interested in the effects of emotions and working memory overload on the decline on the performance of individuals exposed to a stereotype of inferiority (Aronson \& Steele, 2005; Schmader et al., 2008) ${ }^{[44]}$. It is in particular the implications of negative emotions that are analyzed (Kinch, 2017; Schmader et al., 2008) ${ }^{[28,44]}$. These relate to lack of self-confidence, negative performance expectations, discouragement, worries about the task, negative thoughts or obstruction of working memory (Beilock et al., 2007; Cadinu et al., 2005; Steele \& Aronson, 1995) ${ }^{[5,45]}$. From this perspective, functional and cognitive theories of emotions argue that negative evaluation generates negative affects which are, in turn, responsible for avoidance attitudes. These lead to a disengagement from the task and a drop in performance (Chateignier et al., 2011) ${ }^{[12]}$. 
Literature analyzes the emotions relating to the stereotypical threat situation and their mechanisms of action on the observed performance reduction. In this register, anxiety and fear are particularly studied. In fact, individuals exposed to stereotypes of inferiority in a domain are more anxious than people who are not (Katz \& Greenbaum, 1963, cited by Chateignier et al., 2011) ${ }^{[12]}$. Concretely, threatening situations lead to the emergence of an attentional focus bias on the anxiety-inducing signs they produce (Chateignier et al., 2011; Raymondie \& Steiner, 2020) ${ }^{[12]}$. This means that the attention of stigmatized people is more focused on the information produced by the threat. Therefore, with most of the resources at their disposal being requisitioned to deal with the threat, very little remains to be used to complete the task. The logical consequence is the decrease in performance due to anxiety and fear (Cadinu et al., 2005; Johns et al., 2008) ${ }^{[26]}$. In details, fear prompts the individual to flee and avoid the situation that generated it. This situation would lead to a lack of investment in the task, relative to the fear felt; hence the disengagement in the task and the poor performance (Schmader et al., 2008) ${ }^{[44]}$. Anger has similar consequences as fear. Indeed, when faced with an activity that requires cognitive flexibility and that takes environmental factors into account, the anger emanating from the stereotype can inhibit the performance of individuals exposed to a stereotype of inferiority (Chateignier, 2014; Raymondie \& Steiner, 2020) ${ }^{[13]}$. Thus, negative emotions (fear and anger) are responsible for the decline in performance of stereotyped individuals. It emerges from the above elements that in a situation of stereotype threat, there is the emergence of negative emotions which create negative interference, corrupt and overload working memory. All this hinders the process of scheduling mnemonic resources (available in working memory) favorable to efficient processing of information during the execution of the task. The consequence of this process is failure or reduced performance and behavioral tendencies (Raymondie \& Steiner, 2020; Schmader et al., 2008) ${ }^{[44]}$.

Dealing with the emotions generated by the threatening situation has not yet been listed as a strategy for reducing sensitivity to stereotype threat. However, the negative emotions that arise in a situation of threat trigger destabilizing physiological mechanisms that reduce the performance of stereotyped individuals. Likewise, when exposed to a stereotype of inferiority, individuals deploy significant resources to suppress negative, intrusive and inhibitory thoughts and emotions from working memory (Schmader et al., 2008) ${ }^{[44]}$. Thus, while taking the emotional consequences of stereotypes into account, the present research suggests that the specialized literature should be interested in the management of emotions as a strategy of reducing the sensitivity of individuals to the threat of a stereotype of inferiority in a domain. In fact, in a competitive situation, athletes generally experience emotions such as joy, anger, sadness, anxiety, disgust or fear (Laborde et al., 2013; Raymondie \& Steiner, 2020) ${ }^{[31]}$. This means that the practice of a sporting activity (whether it is playful, formative, competitive or for health purposes) generally leaves emotions in its wake (Campo \& Louvet, 2016) ${ }^{[9]}$. These activate physiological parameters and affect athletic performance (Laborde et al., 2016) ${ }^{[30]}$. Thus, a parallel can be drawn between the impact of emotions arising from exposure to a stereotype of inferiority in an activity and the impact of the emotions felt by athletes on their performance; especially since sport is an area of social life. As such, one can activate stereotypes of inferiority for certain groups, as it is the case for women in football (Heidrich \& Chiviacowsky, 2015; Hermann \& Vollmeyer, 2016) ${ }^{[24]}$.

The existing literature does not mention any strategy or emotional factor that could reduce the negative effects of stereotype threat on sports' performance in general and football in particular. However, the works presented in the previous paragraphs reveals that this threat affects individuals on an emotional level. To fill this gap, this study suggests that the ability to manage stereotype-induced emotions is a stereotype threat's reduction factor. This is why it proposes emotional intelligence (EI) as a factor that can reduce sensitivity to stereotype threat, and therefore protect the performance of stigmatized individuals subjected to a task. This proposition is underpinned by the fact that the individual has the capacity to understand his emotions and those of others, and to distinguish it in order to guide his thinking and actions. Indeed, emotional intelligence is conceived as the mental skill centered on the cognitive capacities of individuals (IE-skill) on one hand, and as a personality trait (IE-trait) on the other hand (Bar-On, 1997) ${ }^{[3]}$. The literature reveals that an emotionally intelligent person is able to identify, understand and manifest his emotions for good reflexivity and better adaptability to the situation (Mayer et al., 2004) ${ }^{[35]}$. Likewise, it is established that emotional intelligence can improve sports' performance, by avoiding negative emotions generated by sports activity (Laborde \& Raab, 2016) ${ }^{[31]}$. In this vein, Dosseville et al. (2016) ${ }^{[19]}$ claim that an emotionally intelligent individual is competitive, has strong self-esteem, and readily understands and applies the technical aspects of a sporting event. On the other hand, an athlete who is emotionally affected during the activity will perform less well (Campo \& Louvet, 2016) ${ }^{[9]}$. This is the reason why sport psychology links emotional intelligence to individual functioning in order to limit the damaging effect of emotions (Thelwell et al., 2008) ${ }^{[47]}$. In this domain of knowledge, links have been established between emotional intelligence and management of inter-individual aggression (Dosseville et al., 2016) ${ }^{[19]}$, athletes' state of mind, leadership of managers in physical education (Lane et al., 2009) ${ }^{[32]}$, effectiveness of coaching (Thelwell et al., 2008) ${ }^{[47]}$, performances of athletes in general and sprinters in particular (Lane et al., 2009; Lane $\&$ Wilson, 2011) ${ }^{[33]}$, or social and physical anxiety. Based on these arguments, the hypothesis underlying this study can be formulated as follows: among girls learning to play football, high emotional intelligence reduces sensitivity to stereotype threat more than low emotional intelligence.

\section{Method}

\subsection{Participants}

Sixty-one (61) female pupils from form 4 of the Government Bilingual High School of Penka-Michel (Cameroon), participated in the study (average age $=14.98$ years). They were selected on the basis of the marks obtained at the end of the football session of the sport and physical education's course (marks between 12 and 15 out of 20). The authorization of the Principal was required to conduct the experiment. However, since it took place as part of a normal school activity (a sport and physical education class), the consent of the participants was not required. Despite this, the experimenters have undertaken to respect their anonymity and the use of the data collected during the experiment for strictly scientific purposes.

\subsection{Material}

In the present study, emotional intelligence is assessed using 
the Trait Emotional Intelligence Questionnaire-Adolescent Short Form (TEIQue-ASF) (Petriedes et al., 2006). This instrument is made up of 30 items assessing 4 dimensions of emotional intelligence $(\alpha=.80)$. Six (6) items assess the "well-being", dimension. For example, item 5 states, «I do not find my life pleasant. »Six (6) other items assess the "self-regulation" dimension. For example, item 15 suggests that: «I am able to deal with stress. » The third dimension, "emotionality", is evaluated by 8 items, including item 25 which states: «I tend to let myself go even when I know that I am right. » The fourth dimension, "sociability", has 6 items including item 10, which argues that: « it is difficult for me to defend my rights. » Four (4) items, not belonging to any of the 4 dimensions of the scale, measure the overall trait of emotional intelligence. For example, item 3 suggests that: «I am a very motivated person. » The items of this psychometric instrument are rated on a 7-points Likert scale, ranging from 1 (strongly disagree) to 7 (strongly agree). Thus, the scores above and below the mean $(\mathrm{M}=135)$ correspond respectively to the high and low emotional intelligence. In addition to this scale, the material of this study includes, among other, balls, studs, a stopwatch and a sheet on which the participants' level of emotional intelligence, their anonymity number and the duration of their studs' course is recorded (in thirds).

\subsection{Experimental procedure}

The experimental protocol follows two steps: 1) assessment of participants' emotional intelligence; and 2) application of the stereotype threat's experimental paradigm (Steele \& Aronson, 1995) [45] to women' football. The evaluation of the participants' emotional intelligence was intended to categorize them according to this characteristic of the personality, with a view to the constitution of the groups, necessary for the application of the experimental paradigm. Thus, after the administration of the TEIQue-ASF, participants were distinguished in two groups: one constituted of those with high emotional intelligence and the other with those having low emotional intelligence. After this categorization on the basis of their level of emotional intelligence, they were assigned to groups, following the logic of stereotype threat's experimental paradigm. This paradigm has two conditions: an experimental (diagnostic) and a control conditions (non-diagnostic). The participants' groups are formed such that each level of emotional intelligence (high or low) is represented in each experimental condition. Thus, the control and experimental groups are divided into two subgroups, made up of participants with low emotional intelligence (control/experimental subgroups 1) and participants with high level of emotional intelligence (control/experimental subgroups 2).

Following the logic of the stereotype threat's experimental paradigm (Steele \& Aronson, 1995) ${ }^{[45]}$, the experimental treatment activates the stereotype of incompetence in the domain of women' football. This is done exclusively in the diagnostic condition (experimental subgroups 1 and 2), while in the non-diagnostic condition, that stereotype is not activated (control subgroups 1 and 2). Concretely, the participants of the two experimental subgroups receive the information according to which the test to which they will be subjected aims to evaluate their footballing performances, in order to compare them with those of the pupils of the same sex attending other high schools of the region. In addition, they are told that the study aims to understand and explain why girls perform less than boys in football. They are also told that around $90 \%$ of footballers (a dummy figure) believe that this sport is not an activity for girls and that it should be played only by boys. The aim of this procedure is the reinforcement of the stereotype of women' incompetence. To back up the information given to the participants, the experimenters gave them "statistical sheets from the National Institute of Statistics", a state body particularly specialized in surveys in various sectors of activity. These fact sheets report statistics that support the information provided to them and in fact corroborate the stereotype of women' incompetence in the domain of football (dummy aspect of the experience). Participants of the non-diagnostic condition are simply informed that this is a training session for young footballers in preparation for the upcoming games of the National Federation for College and University Sports.

After participants are exposed to the stereotype of incompetence, they are tested. In practice, following Beilock et al.'s (2007) ${ }^{[5]}$ procedure, each of them had to drive the ball on a sinusoidal rectilinear course made up of six (6) studs, "back and forth". They had to go around the six studs (numbered 1 to 6) so as to pass the ball consecutively between the spaces that separate them. We specify that the distance between two studs, aligned along a rectilinear path, is one meter. At the end of the "outward" path, that is to say at the level of the sixth stud, they had to go around the latter in a rotary manner, in order to start the "return" course of the same process leading to the first block. In order to ensure the complexity of the task, the experimenters instruct the participants to drive the ball with only one foot (the most skilled or able foot) and to avoid it touching the studs (O'Brien \& Crandall, 2003) ${ }^{[38]}$. Therefore, the change of foot or the contact between the ball and the stud were considered as faults. In these cases, they had to stop and reposition the ball at the point preceding the one where the foul was committed. They have been informed that their performance is assessed on the basis of the duration of their journey, which is subjected to time measurement (in thirds). They passed the test individually.

\section{Results}

The results of this study are presented in two phases. The first reports descriptive statistics relating to the distribution of trends observed in each experimental condition (Means and Standard Deviations). The second reports inferential analyzes (intergroup and intragroup analysis of variances (ANOVA)). It is applied due to the fact that the experimental protocol makes it possible to compare experimental and control subgroups. This statistical test presents the level of differences between groups and the significance of these differences, in order to determine to what extent emotional intelligence reduced the effect of stereotype threat on participants' performances. 


\subsection{Descriptive statistics analyzes}

Table 1: Presentation matrix of the Means (M) Standard Deviations (SD) of the tendancies observed in each group

\begin{tabular}{|ll|c|c|c|c|c|}
\hline & N & Minimum & Maximum & M & SD \\
\hline $1-$ & Experimental subgroup 2 (high IE) & 18 & 1920 & 6480 & 3566.67 & 1483.636 \\
\hline 2- & Experimental subgroup 1 (Low IE) & 16 & 2100 & 5340 & 3618.75 & 1006.789 \\
\hline 3- & Control subgroup 2 (High IE) & 11 & 1364 & 7200 & 3433.72 & 2196.979 \\
\hline 4- & Control subgroup 1 (Low IE) & 16 & 220 & 5280 & 3182.25 & 1368.370 \\
\hline 5- & Experimental group (Low and high IE) & 16 & 400.00 & 11220.00 & 5889.00 & 3360.999 \\
\hline 6- & Control group (Low and high IE) & 16 & 220.00 & 10920.00 & 4434.35 & 3547.906 \\
\hline \multicolumn{2}{r|}{ Valid number (list) } & 11 & & & & \\
\hline
\end{tabular}

Note: The average journey times reflect the average performance of the subgroups. An asymmetric relationship exists between the time taken and the performance achieved (the smaller the time, the greater the performance)

This table presents the statistical distributions of the tendencies observed in each subgroup. It reveals that participants in Experimental Subgroup 1 (low EI, $\mathrm{M}=$ 3618.75; $\mathrm{SD}=1006.78$ ) performed less than those in Experimental Subgroup 2 (high EI, $\mathrm{M}=3566.67$; $\mathrm{SD}=1483$, 63). When we compare the experimental 2 (high IE, $\mathrm{M}=$ 3566.67; $\mathrm{SD}=1483.63$ ) and control 2 (high IE, $\mathrm{M}=3433.72$; $\mathrm{SD}=2196.979$ ) subgroups, we realize that the participants of this control subgroup performed better than those of the experimental subgroup; indicating that the stereotype of incompetence they have been exposed to may have impacted their performance. The same tendencies are confirmed when we compare the control 1 (low EI, $\mathrm{M}=3182.25$; $\mathrm{SD}=$ 1368.37) and experimental 1 subgroups (low IE, $\mathrm{M}=$ 3618.75; SD = 1006.789). Thus, overall, participants who were not exposed to the stereotype of incompetence performed better than their counterparts who have been exposed to it. Indeed, the experimental group (low and high IE, $\mathrm{M}=5889.00 ; \mathrm{SD}=3360.999$ ) performed less than the control group (low and high IE, $\mathrm{M}=4434.35$; $\mathrm{SD}=$ 3547.906), without distinction of emotional intelligence level.

\subsection{Intergroup and intragroup analysis of variances (ANOVA)}

Table 2: Analysis of variance between experimental (1 and 2) and control (1 and 2) subgroups and between experimental and control groups

\begin{tabular}{|c|c|c|c|c|c|c|c|c|}
\hline & $\sum$ of squares & $d f$ & Mean square & $f$ & $D^{2}$ & $p$ & $t$ & $p$ \\
\hline \multicolumn{9}{|c|}{ Main result of the validation of the research hypothesis } \\
\hline 1. Experimental subgroup 2 (high EI) * Experimental subgroup 1 (low EI) & 32125500.0 & 13 & 2471192.3 & 6.79 & 98. & .135 & .63 & .532 \\
\hline \multicolumn{9}{|c|}{ Secondary results obtained } \\
\hline 2. Experimental subgroup 2 (high IE) $*$ Control subgroup 2 (high IE) & 32799420.0 & 11 & 2981765.4 & 223.85 & .99 & .000 & 3.72 & .002 \\
\hline 3. Experimental subgroup 1 (low EI) * Control subgroup 1 (low EI) & & 14 & 312.5 & 24.06 & 76 & .159 & 1338.2 & 827 \\
\hline 4. Experimental group $*$ Control group & 212862580.0 & 16 & 13303911.2 & 22.58 & .78 & .013 & 1682.91 & .007 \\
\hline
\end{tabular}

Following a normal distribution of the population, this table presents two subgroups with high and low EI in diagnostic condition (experimental subgroup 2 (high EI) and experimental subgroup 1 (low EI)). It indicates that there is a difference between the performance of the participants of experimental subgroup 2 (high EI, $\mathrm{M}=3566.67$; $\mathrm{SD}=$ 1483.63) and those of experimental subgroup 1 (low EI, $\mathrm{M}=$ 3618.75; SD = 1006.78). But, this difference is not significant $\left(\mathrm{f}(1,61)=6.79 ; \mathrm{D}^{2}=.98 ; \mathrm{p}=.135>.05 ; \mathrm{t}=.63 ; \mathrm{p}=\right.$ $.532>.05)$. Therefore, this result does not support the hypothesis tested in the present study.

In addition to the results presented above, we observe that the variance between the experimental 2 (high IE, $\mathrm{M}=3566.67$; $\mathrm{SD}=1483.63$ ) and control 2 (high IE, $\mathrm{M}=3433.72$; $\mathrm{SD}=$ 2196.97) subgroups reveals that the performances of the participants differ significantly, in favor of the control 2 subgroup $\left(\mathrm{f}(2,61)=223.85, \mathrm{D}^{2}=.99, \mathrm{p}=.000<.05 ; \mathrm{t}=3.72\right.$, $\mathrm{p}=.002<.05)$. We also note that the performances of experimental 1 (IE Low, $\mathrm{M}=3618.75 ; \mathrm{SD}=1006.78$ ) and control 1 subgroups (IE Low, $\mathrm{M}=3182.25$; $\mathrm{SD}=1368.37$ ) whose members have a low emotional intelligence do not differ significantly $\left(\mathrm{f}(3,61)=24.06, \mathrm{n}^{2}=.76, \mathrm{p}>.05 ; \mathrm{t}=\right.$ $1338.2, \mathrm{p}=.827>.05)$. This explicitly means that participants who have low emotional intelligence and who have been exposed to the stereotype of incompetence perform almost similarly to their counterparts with the same level of emotional intelligence, but who were not exposed to that stereotype. Overall, the intergroup variance (experimental and control groups) indicates that the performance of participants differed significantly, in favor of the control group, not exposed to the stereotype of incompetence in the domain of football $\left(\mathrm{f}(4,61)=22.58, \mathrm{D}^{2}=.78, \mathrm{p}=.013<.05 ; \mathrm{t}=\right.$ $1682.91, \mathrm{p}=.007<.05)$. 


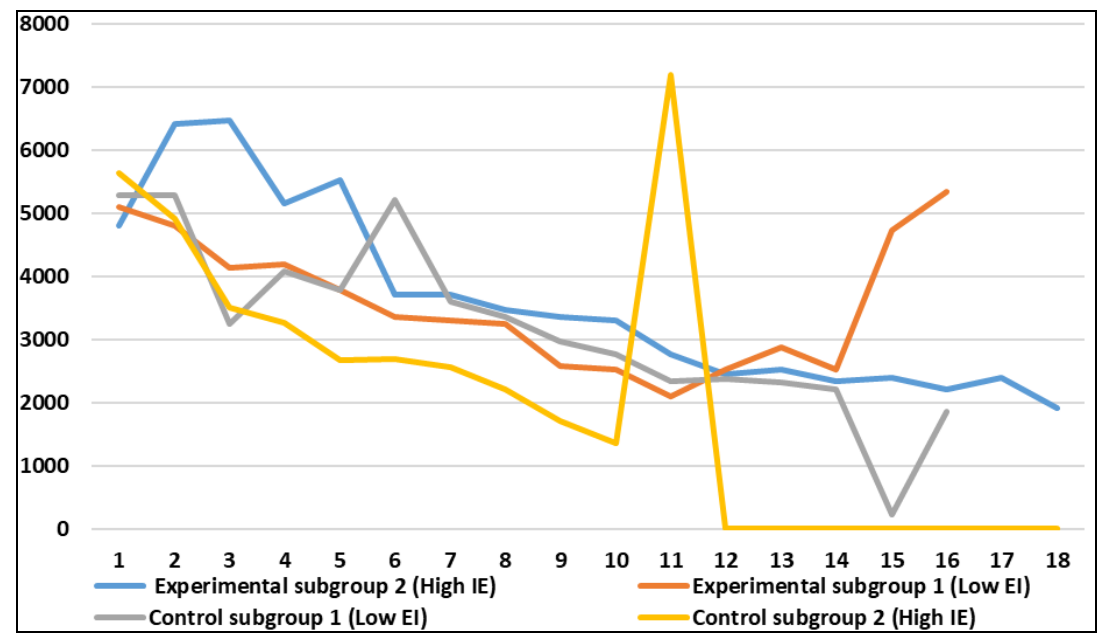

Fig 1: Curve of variation in the performance of participants under experimental and control conditions having respectively high and low EI

The performance variation curves of the stereotyped groups with high and low emotional intelligence reveal that the performances of the two experimental subgroups show a different monotonicity, although this is not significant. Indeed, the evolution curve of the football performances of the members of experimental subgroup 2 can be analyzed in several phases depending on whether one evolves along the lines of the abscissas X (from 0 to 18) and of the ordinates $\mathrm{Y}$ (from 0 to 7000). It increases when $X$ takes the approximate values going from 0.5 to 1.5 and thus describes a performance which varies between approximately 4800 and 6500 thirds, then remains constant when $\mathrm{X}$ goes from 1.5 to 2.5 . A decrease in performance is observed when $\mathrm{X}$ goes from 2.5 to 3.4; and a slight increase in performance is noted when $\mathrm{X}$ varies between 3.8 to 4.8 before gradually decreasing. The performance variation curve of the members of experimental subgroup 1 (low IE), for its part, gradually decreases, when the values of $\mathrm{X}$ go from 0.5 to 10.5 approximately, those of $\mathrm{Y}$ decrease from 5000 to 2000 . These performances reach their paroxysm (with a value of Y appreciably close to 5000) when $\mathrm{X}$ passes from 13.5 to 15.5 approximately. The difference in average performance evaluated at 52.08 points begins at the intersection points between the two curves, the first of which is located at level $\mathrm{Y}=5000$ and the second at level $\mathrm{Y}=2500$ approximately. But, this difference which is in favor of experimental subgroup 2 is not significant.

Experimental 2 and Control 2 subgroups, when put together, also show monotonic variations. In fact, the performance variation curve for control subgroup 2 effectively shows a different monotonicity from that of experimental subgroup 2. It decreases when the values of $\mathrm{X}$ go from 1 to 10 . It increases significantly when $\mathrm{X}$ takes the values ranging from 10 to 12 , reaching a peak performance equal to approximately 7200 . It is at this level (at the inflection point) that performance increases significantly when changing slope ( $\mathrm{X}$ tending towards 0). It should be remembered that when the football performance curve decreases, it means that the participant takes less time to drive the ball on a sinusoidal straight path "back and forth" and achieves a good performance. Meanwhile, the football performance curves of Experimental Subgroups 1 and 2, and those of Control Subgroup 1 do not cancel each other out.

\section{Discussion}

The hypothesis tested in this research was that among girls learning to play football, high emotional intelligence reduces sensitivity to stereotype threat more than low emotional intelligence. Thus, emotional intelligence is seen as a factor that can protect individuals from the negative effects of a stereotype of incompetence. In practical terms, participants with high emotional intelligence would perform better than their counterparts with low emotional intelligence. The data collected does not provide empirical support for the prediction tested in this study, although there is a difference in performance between the two groups, in favor of the former. They also reveal that in the case of individuals with high emotional intelligence, exposure to the stereotype of incompetence significantly impacted participants' performance; those who have been exposed to it perform less than those who have been preserved. Clearly, despite high emotional intelligence, exposure to a stereotype of incompetence affects performance in the execution of a task. These observations are not made in cases where the participants' emotional intelligence is low.

The results of the present study do not agree with what the literature predicts. Indeed, Brasseur and Grégoire (2010) assert that emotional intelligence and cognitive intelligence impact on the development of the individual. According to them, these two variables have positive or even symmetrical links with academic and/or professional success. They contribute to better physical and mental health, and therefore promote better social integration. In this vein, we note that the EI-trait is linked to the intelligence quotient (IQ) of adolescents. In fact, these authors explain that teens with high IQs are not necessarily the most emotionally intelligent. This means that just because an individual has high emotional intelligence does not necessarily mean that he is intelligent or that he can perform well if we associate performance, achievement or success with IQ. It would then be better to consider that there would be an asymmetric link between emotional intelligence and intelligence quotient. While football performance can be associated with a footballer's IQ, the emotional intelligence analyzed in this study would be asymmetrically linked to the IQ values of stereotyped individuals. According to Petriedes et al. (2006), students with a low IQ have more difficulty completing tasks. Therefore, they need non-cognitive skills such as emotional intelligence to overcome obstacles. In other words, high emotional intelligence is more important for individuals with low cognitive abilities. Those with a high IQ seem to need no other abilities to be successful (Mikolajczak, 2009). Whether emotional intelligence is high or low, stereotyped individuals perform roughly the same. Thus, a high emotional intelligence does not protect the working memory against the deleterious 
effects of the stereotype, and therefore does not guarantee good performance.

The results of the present study may find further convincing explanations in the fact that the participants were confronted with a situation characterized by a double emotional burden. The reason is that sport, like the stereotype of incompetence, generates an emotional load which hinders the working memory of the individual (Schmader et al., 2008) ${ }^{[44]}$. As a reminder, sporting activities have a reputation for inducing strong emotions in athletes, these activate the central nervous system and cognitive processes that are not very favorable to performance (Campo \& Louvet, 2016; Laborde et al., 2013) ${ }^{[9,}$ 31]. The stereotype threat acts in the same way. It triggers negative emotions. The latter, for their part, overload the working memory and prevent the individual from having recourse to the intellectual resources that allow him to efficiently perform a task requiring mnemonic capacities (Chateignier, 2011; Schmader et al., 2008) ${ }^{[12,44]}$. This double emotional load can have the effect of inducing a high level of stress, thus causing cognitive immobility (Goleman, 1997). For this author, cognitive immobility inhibits an individual's intellectual capacities and prevents him from concentrating when performing a task. That is, the emotional brain has the capacity to subjugate and paralyze the thinking brain, if the emotional load is too high (Goleman, 1997). The double emotional burden is said to have inhibited emotional intelligence and its reducing effect on stereotype threat; which means that it infers on individuals' performances. We can notice that the evaluation of this ability to manage emotions which is done in the current study through a self-reported measure (the TEIQue-ASF of Petriedes et al., 2006) just enable us to have a score that allows to determine the level of emotional intelligence. This score represents the individual's ability to regulate the emotions responsible for the mental load generated by stereotype threat. This score does not indicate whether the process of regulating emotions was actually initiated by the participants. It reveals the existence of a potential for regulating emotions, which is not an effective regulation of those emotions.

\section{References}

1. Ambady N, Paik SK, Steele J, Owen-Smith A, Mitchell JP. Deflecting negative self-relevant stereotype activation: The effects of individualisation. Journal of Experimental Social Psychology 2004;40:401-408.

2. Aronson J, Steele CM. Stereotypes and the fragility of human competence, motivation, and self-concept. In C. Dweck \& E. Elliot (dir.), Handbook of Competence \& Motivation. Guilford 2005.

3. Bar-On R. The Emotional Quotient Inventory (EQ-i): Technical manual. Multi-Health Systems, Inc 1997b.

4. Beilock SL, McConnell AR. Stereotype threat and sport: Can athletic performance be threatened? Journal of sport \& exercise psychology 2004;26:597-609.

5. Beilock SL, Jellison WA, Rydell RJ, McConnell AR. Stereotype threat and woorking memory: mechanism, alleviation, and spillover. Journal of Experimental Psychology: General 2007, 136-276.

6. Beilock SL, Jellison WA, Rydell RJ, McConnell AR, Carr TH. On the causal mechanisms of stereotype threat: Can skills that don't rely heavily on working memory still be threatened? Personality and Social Psychology Bulletin 2006;32:1059-1071.

7. Brasseur S, Grégoire J. L'intelligence émotionnelle-trait chez les adolescents à haut potentiel : Spécificités et liens avec la réussite scolaire et les compétences sociales. Enfance 2010;1:59-76.

8. Cadinu M, Maass A, Rosabianca A, Kiesner J. Why do women underperform under stereotype threat? American Psychological Society 2005; $16: 572-578$.

9. Campo M, Louvet B. Les émotions en sport et en EPS: Apprentissage, performance et santé. De Boeck Supérieur 2016.

10. Chalabaev A, Sarrazin P, Stone J, Cury F. Do achievement goals mediate stereotype threat? An investigation on females' soccer performance. Journal of Sport and Exercise Psychology 2008;30:143-158.

11. Chalabaev A, Stone J, Sarrazin P, Croizet JC. Investigating physiological and self-reported mediators of stereotype lift effects on a motor task. Basic and Applied Social Psychology 2008;30:18-26.

12. Chateignier C. Le rôle des émotions dans la menace de stéréotype : Comment les émotions sont-elles impliquées dans l'impact des mauvaises réputations sur la performance des individus stigmatisés? Université Paris Ouest Nanterre-La Défense 2011.

13. Chateignier C. Les femmes sont nulles en mathématiques. Je suis une femme donc je vais échouer: Comment les stéréotypes négatifs détériorent-ils les performances des individus stigmatisés? Revue Électronique de Psychologie Sociale 2014;6:34-41.

14. Chateignier C, Dutrévis $M$, Nugier A, Chekroun P. French-Arab students and verbal intellectual performance: Do they really suffer from a negative intellectual stereotype? European Journal of Psychology of Education 2009;24:219-234.

15. Chateignier C, Chekroun P, Nugier A, Dutrévis $M$. Femme au volant... Effet de la menace du stéréotype et de la colère sur les performances des femmes à une tâche liée à la conduite automobile. L'Année psychologique 2011;4(111):673-700.

16. Clément-Guillotin C, Fontayne P. Situational malleability of gender schema: The case of the competitive sport context. Sex Roles 2011;64:426-439.

17. Dagot L. Menace du stéréotype et performance motivationnelle: le cas des demandeurs d'emploi. L'orientation scolaire et professionnelle 2007;36(3):1147. http://journals.openedition.org/osp/1452; DOI: 10.4000/osp. 1452

18. Desmette D, Bourguignon D, Herman G. Menace du stéréotype et déficit cognitif:une étude des processus auto-handicapants. In H. Paugam-Moisy, V. Nyckees, J. Caron-Pargue (Eds.), La cognition entre individu et société, Hermes-Lavoisier 2001, 57-68. http://hdl.handle.net/2078.1/178664

19. Dosseville F, Laborde S, Allen M. L'intelligence émotionnelle dans le sport. In Campo, M. \& Louvet, B. (Eds.), Les émotions en sport et en EPS : Apprentissage, performance et santé De Boeck Supérieur 2016, 243-261.

20. Goleman D. L'Intelligence Émotionnelle: comment transformer ses émotions en intelligence. Robbert Laffont 1997.

21. Good C, Aronson J, Inzlicht M. Improving adolescents' standardized test performance: An intervention to reduce the effect of the stereotype threat. Applied Developmental Psychology 2003;24:645-662.

22. Grabow H, Kühl M. You don't bend it like beckham if you're female and reminded of it: Stereotype threat among female football players. Frontiers in psychology 2019;10:1963. https://doi.org/10.3389/fpsyg.2019.01963 
23. Heidrich C, Chiviacowsky S. Stereotype threat affects the learning of sport motor skills. Psychology of Sport and Exercise 2015;18:42-46.

24. Hermann JM, Vollmeyer R. Girls should cook, rather than kick! Female soccer players under stereotype threat. Psychology of Sport and Exercise 2016;26:94-101.

25. Hill JL, Azzarito L. Challenging a man's game: women's interruption of the habitus in football. Paper presented at the British Educational Research Association Annual Conference, University of Manchester 2009.

26. Johns M, Inzlicht M, Schmader T. Stereotype threat and executive resource depletion: Examining the influence of emotion regulation. Journal of Experimental Psychology: General 2008;137:691-705.

27. Johns M, Schmader T, Martens A. Knowing is half the battle. Psychological Science 2005;16:175-178.

28. Kinch SB. L'effet de la menace du stéréotype sur le rendement des élèves en orthographe (Mémoire de Master). Université du Québec À Montréal 2017. https://archipel.uqam.ca/12002/1/M15136.pdf

29. Laborde S, Raab M. Comment les émotions influencent t'elles la prise de décision du sportif? Université Allemande du Sport de Cologne. Psychologist 2016;35:151-175.

30. Laborde S, Dosseville F, Allen MS. Emotional intelligence in sport and exercise: A systematic review. Scandinavian Journal of Medicine \& Science in Sports targets' test performance and subjective experience. British Journal of Social Psychology 2016;44:645-657.

31. Laborde S, Dosseville F, Raab M. Emotions and decision making in sports: Introduction, comprehensive approach, and vision for the future. International Journal of Sport \& Exercise Psychology 2013;11:143-150.

32. Lane AM, Wilson M. Emotions and trait emotional intelligence among ultra-endurance runners. Journal of Science \& Medicine in Sport 2011;14:358-362.

33. Lane AM, Thelwell RC, Lowther J, Devonport TJ. Emotional intelligence and psychological skills use among athletes. Social Behavior \& Personality 2009;37:195-202.

34. Marx DM, Goff PA. Clearing the air: The effect of experimenter race on targets test performance and subjective experience. British Journal of Social Psychology 2005;44:645-657.

35. Mayer JD, Salovey P, Caruso DR. A further consideration of the issues of emotional intelligence. Psychological Inquiry 2004;15:249-255.

36. De Meyer M. L'enseignement de la menace de stéréotype à l'école peut-il faire réduire son impact négatif sur la performance des individus stigmatisés: le cas du stéréotype des hommes en orthographe? 2015. https://dumas.ccsd.cnrs.fr/dumas-01305467/document

37. Mikolajczak M. Going beyond the ability-trait debate: The three leve! mode! of emotional intelligence. Electronic Journal of Applied Psychology 2009;5(2):2531.

38. O'Brien LT, Crandall CS. Stereotype threat and arousal: Effects on women's math performance. Personality and Social Psychology Bulletin 2003;29:782-789.

39. Pfiter G. Assessing the sociology of sport: on women and football. International Review of Sociology of Sport 2015;50:563-569.

40. Racky K. Menace (s) du stéréotype et perception de soi: Comment modérer l'impact des réputations négatives sur les membres des groupes stéréotypés ? Le cas des femmes et des Noirs de France. Psychologie. Université René Descartes-Paris. Français. ffNNT 2013 PA05H105ff. fftel00838404f

41. Raymondie R, Steiner DD. Stéréotypes de genre concernant l'expression des émotions: pensez subordonné-pensez femme? In C. Lagabrielle, D. Steiner et A. Battistelli (eds) Carrières, leadership et conflits. L'Harmattan 2020. ffhal-02877275f

42. Sales-Wuillemin É. Catégorisation et représentations sociales. In M., Bromberg, \& A. Trognon (eds.), Cours de psychologie sociale Presses Universitaires de France 2007;2:7-32.

43. Schmader T, Johns M. Converging evidence that threat reduces working memory capacity. Journal of Personnality and Social Psychology 2003;85:449-452.

44. Schmader T, Johns M, Forbes C. An integrated process model of stereotype threat effects on performance. Psychological Review 2008;115:336-356.

45. Steele CM, Aronson J. Stereotype threat and the intellectual test performance of African Americans. Journal of Personality and Social Psychology 1995;69:797-811.

46. Steele CM, Spencer SJ, Aronson J. Contending with group image: The Psychology of Stereotype and Social Identity Threat. In M. P. Zanna (Ed.), Advances in Experimental Social Psychology Academic Press 2002, 277-341.

47. Thelwell RC, Lane AM, Weston NJV, Greenlees I. Examining relationships between emotional intelligence and coaching efficacy. International Journal of Sport \& Exercise Psychology 2008;6:224-235. 